\title{
Repeated alcoholic \\ intoxication compared with continued consumption of dilute ethanol in experiments with rats on a marginal diet
}

\author{
BY HENRIK WALLGREN, JOHAN AHLQVIST, KURT ÅHMAN \\ AND HEIKKI SUOMALAINEN
}

Research Laboratories of the State Alcohol Monopoly (Alko), Helsinki, Finland

(Received 19 December 1966-Accepted 2 March I967)

\begin{abstract}
I. The effects have been compared of long-term administration of similar amounts of ethanol given either diluted in drinking water or spaced out in the form of intoxicating doses.

2. The effect of ethanol on the development of liver lesions produced by a marginal diet was examined. The measurements of growth rate, water balance, plasma glucose and electrolytes, rate of ethanol elimination, and some behavioural tests for the detection of tolerance and possible signs of neurological disturbance were also included.

3. Isocalorically pair-fed growing male rats were subjected to three different regimens for 6 months: (A) ethanol solution as the sole drinking fluid with 2 days' intake adjusted to approximately $5 \mathrm{mg} / \mathrm{g}$ body-weight; (B) a similar quantity of ethanol given as a single intoxicating dose per os on alternate days; (C) oleic acid isocaloric with the ethanol per os on alternate days.

4. All the regimens caused fatty liver. Hepatic fibrosis, as judged macro- and microscopically, was equally severe after treatments $\mathrm{A}$ and $\mathrm{C}$, but milder after treatment $\mathrm{B}$.

5. Growth was retarded by intoxication, which also brought about a large increase in water consumption, without exerting other clear effects on water balance or on plasma electrolytes. The rate of ethanol elimination was increased by repeated intoxication. Behavioural tolerance of the effects of ethanol was also found in the animals subjected to intoxication.
\end{abstract}

Nutritional and pharmacological factors both produce effects on the organism after long use of alcoholic beverages. The amount of ethanol consumed determines its role in the nutritional balance, whereas the temporal distribution of the intake is decisive for the intensity of the pharmacological effects. Improvement in the differentiation between these two aspects of the action of ethanol would serve to advance our understanding of how the hazards involved in the use of alcoholic beverages could be mitigated. Notwithstanding the importance of these considerations, little systematic exploration of the respective roles of the pharmacological and the nutritional effects of ethanol has been made. In long-term experiments with animals, the most common technique has been to provide ethanol solution as the sole source of fluid. Reports have been published also on various effects of intoxicating doses repeated over prolonged periods. There does not seem, however, to be any report of studies in which other conditions have been kept constant, and only the method of administration of a given quantity of ethanol has been varied. The purpose of the present study was to examine this approach, and find criteria for further investigations along similar lines. A further aim was to simulate conditions of a regular but relatively moderate drinking pattern, rather than heavy drinking. A brief preliminary report has been published (Wallgren \& Suomalainen, 1966). 


\section{EXPERIMENTAL}

\section{Criteria of ethanol effects}

As the study was exploratory, broad criteria were chosen. Fatty infiltration and fibrosis of the liver objectively show effects of a nutritional regimen producing lesions of the liver. In view of the uncertainty concerning the aetiology of the liver pathology in chronic alcoholics (Lieber, 1965), the question arises whether repeated alcoholic intoxication superimposed on such a regimen would accelerate the appearance of liver lesions.

As it is easier to produce nutritional fibrosis in growing rats than in adult ones, young animals were used and the growth rate was a natural criterion. Information on electrolyte and fluid balance was sought by the measurement of plasma electrolytes and total body water at the end of the experimental period. Blood sugar and the rate of ethanol elimination were taken as measures of metabolic alterations. To detect tolerance and hyperexcitability, a few simple tests of behaviour and motor co-ordination were made.

Table I. Mean values and ranges for weight, weight gain, feed and fluid consumption at the beginning of pair-feeding in the three groups of twenty-five animals on the different treatments

(Weight gains refer to the selection period of 2 weeks preceding pair-feeding)

\begin{tabular}{|c|c|c|c|c|}
\hline Group & $\begin{array}{l}\text { Weight } \\
\text { (g) }\end{array}$ & $\begin{array}{c}\text { Weight } \\
\text { gain } \\
\text { (g/2 weeks) }\end{array}$ & $\begin{array}{c}\text { Feed } \\
\text { consumed } \\
(\mathrm{g} / \text { day })\end{array}$ & $\begin{array}{c}\text { Water } \\
\text { consumed } \\
(\mathrm{g} / \text { day })\end{array}$ \\
\hline A (drinking) & $\begin{array}{c}140 \\
(121-156)\end{array}$ & $\begin{array}{c}15 \cdot 0 \\
(8-23)\end{array}$ & $\begin{array}{c}7 \cdot 3 \\
(6 \cdot 8-8 \cdot I)\end{array}$ & $\begin{array}{c}27 \cdot 8 \\
(20-36)\end{array}$ \\
\hline B (intoxication) & $\begin{array}{c}140 \\
\left(123^{-1} 55\right)\end{array}$ & $\begin{array}{c}15 \cdot 7 \\
(8-34)\end{array}$ & $\begin{array}{c}7 \cdot 4 \\
(6 \cdot 9-8 \cdot r)\end{array}$ & $\begin{array}{c}26 \cdot I \\
(19-35)\end{array}$ \\
\hline $\mathrm{C}$ (control) & $\begin{array}{c}140 \\
(\mathrm{I} 2 \mathrm{I}-\mathrm{I} 55)\end{array}$ & $\begin{array}{c}15.5 \\
(8-23)\end{array}$ & $\begin{array}{c}7 \cdot 4 \\
(6 \cdot 7-8 \cdot I)\end{array}$ & $\begin{array}{c}26 \cdot 1 \\
(20-34)\end{array}$ \\
\hline
\end{tabular}

\section{Feeding technique}

The study was based on a pair-feeding technique. Preliminary experiments showed that growth and liver condition of animals drinking dilute ethanol and of those drinking water were similar, whereas intoxication retarded growth. As a check on the calorigenic effect of the repeated doses of ethanol, in the final experiment animals received by gavage an amount of oleic acid isocaloric with the ethanol.

The rats were selected from 140 male rats of the laboratory stock which originates from a Wistar strain. At the age of 6 weeks, they were placed in individual cages with grid floors, and given a marginal diet. With food and water consumption and weight gain during the next 2 weeks taken as a basis, twenty-five pair-feeding blocks were formed, each comprising three animals matched for food and water intake and weight gain. As extremes were excluded, the final material of seventy-five animals displayed only a small variability (Table $\mathbf{I}$ ).

The experimental arrangement is illustrated in Fig. I. In each pair-feeding block, 
one animal received $a d l i b$. a dilute ethanol solution in tap water as sole fluid (group A, drinking). During the first 3 weeks, the amount of ethanol was gradually increased from 2.5 to $5 \mathrm{mg}$ absolute alcohol/g body-weight in 2 days. This average consumption was then maintained by adjusting the concentration, which accordingly varied from 3 to $9 \%(\mathrm{v} / \mathrm{v})$. The amount of food given to $\mathrm{A}$ was determined by the consumption of the second animal, B, in the pair-feeding block, which received food ad lib. and, in addition, on alternate days, an amount of ethanol isocaloric with that consumed by animal $\mathrm{A}$, by stomach tube as a $25 \%(\mathrm{w} / \mathrm{v})$ solution in tap water. The third animal (C) was given the same amount of food as consumed by $\mathrm{B}$, and on alternate days by gavage, an amount of oleic acid isocaloric with the ethanol drunk by A during the previous

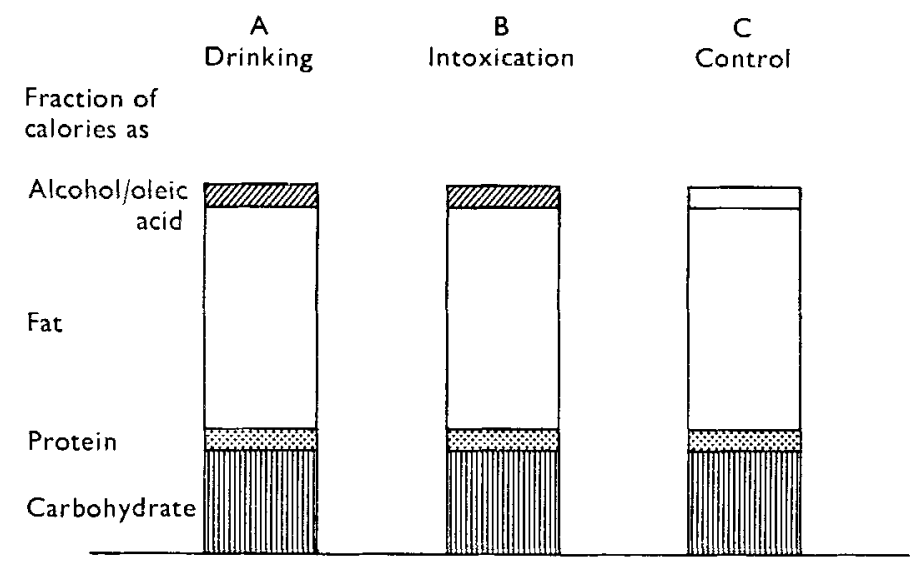

Fig. I. Diagrammatic representation of pair-feeding arrangement. The rats were given a highfat, low-protein diet; those in group $B$ were fed $a d$ lib. and those in groups $\mathrm{A}$ and $\mathrm{C}$ were given the same amount as was eaten by the group B rats. A, drinking: ethanol given in the drinking fluid to an amount of approximately $5 \mathrm{mg} / \mathrm{g}$ body-weight in 2 days. B, intoxication: similar amount of ethanol by gavage on alternate days. C, control: an amount of oleic acid isocaloric with the ethanol by gavage on alternate days.

2 days. The animals of groups $\mathrm{B}$ and $\mathrm{C}$ drank tap water ad lib. The quantities of food, ethanol and oleic acid given to the animals on restricted regimens were adjusted for variations in body-weight as found by weekly weighings, a method considered preferable to the usual practice of administering the same absolute amount to each of the pair-fed animals. Complications arose when animals in groups $\mathrm{A}$ or $\mathrm{C}$ refused to consume all their food. A careful check was kept on the quantities remaining; when possible these were fed subsequently. The consistency of the food made the loss minimal and facilitated the collection of dropped or uneaten portions. To offset effects of handling, the animals in group A also received a gastric intubation every other day without fluid injection. The temperature of the animal room was maintained at about $24^{\circ}$.

The composition of the feed was modified from that described by Ahlqvist (1960), which was based on diet L VI of György \& Goldblatt (I949). The choice of a protein content which should induce a variable degree of fibrosis was based on the results of pilot experiments partly described by Suomalainen, Wallgren \& Åhman (1965). The 
basic diet contained $9 \%$ crude casein, $44 \%$ sucrose, $38 \%$ purified lard, $4 \%$ HawkOser salt mixture (Hawk, Oser \& Summerson, 1954, p. 1375), and $2 \%$ cod-liver oil.

Weekly each $\mathrm{kg}$ of the basic feed was supplemented by $4.29 \mathrm{~g}$ cystine, $7^{\cdot} \cdot 15 \mathrm{mg}$ thiamine hydrochloride, $2.92 \mathrm{mg}$ riboflavine, $4.29 \mathrm{mg}$ pyridoxine hydrochloride, $14.6 \mathrm{mg}$ calcium pantothenate, and $14.6 \mathrm{mg}$ nicotinic acid; the feed was stored in a cold-room, and weighed into the food jars every day. The animals were given, 5 and I I days after starting on the diet, $20 \mathrm{mg}$ of choline chloride to prevent kidney lesions. Once a week, each animal received $5 \mathrm{mg} \alpha$-tocopheryl acetate, pipetted on top of the feed.

Table 2. Mean values and standard deviations for daily calorie intake (kcal/100 g body-weight) in the three groups of fifteen animals completing the experiment

$\begin{array}{ll}\begin{array}{l}\text { Source of } \\ \text { calories }\end{array} & \begin{array}{c}\text { Group A } \\ \text { (drinking) }\end{array} \\ \text { Feed } & 23 \cdot \mathrm{I} \pm \mathrm{r} \cdot 0 \\ \text { Alcohol } & \mathrm{I} \cdot 57 \pm 0 \cdot 07 \\ \text { Oleic acid } & \end{array}$

$\begin{array}{cc}\begin{array}{c}\text { Group B } \\ \text { (intoxication) }\end{array} & \begin{array}{c}\text { Group C } \\ \text { (control) }\end{array} \\ 23.8 \pm \mathbf{I} \cdot 5 & 23 \cdot 0 \pm \mathrm{I} \cdot 3 \\ \mathrm{I} \cdot 63 \pm 0.02 & - \\ - & \mathbf{I} 63 \pm 0.02\end{array}$

The regimen was continued for a total of 178 days, plus 14 days on the marginal diet before the pair-feeding began. Time is quoted below in days or weeks from the start of the pair-feeding. During the experimental period, $6 \%$ of the total calories was provided as protein, $29 \%$ as carbohydrate, $59 \%$ as fat and $6 \%$ as ethanol. The total calorie intake of the animals showed little variation (Table 2), and the calorie loss attributable to the failure of animals $\mathrm{A}$ and $\mathrm{C}$ to consume all their rations was negligible. The consumption of fluids by the animals drinking dilute ethanol was measured throughout the experiment as described above. The water consumption of animals $\mathrm{B}$ and $\mathrm{C}$ was measured on the occasions specified below.

Deaths during the course of the experiment were too few to provide an indication of the differing effects of the treatments. When deaths occurred, the remaining animals in the pair-fed block were discarded. The accidental administration intraperitoneally of ethanol at too high a concentration when the tolerance was measured on day 155 of the experiment led to the loss of six of the twenty-one pair-fed blocks that still remained. The complete results have been used in the final analysis. A separate evaluation of the values for the three groups of fifteen animals surviving throughout the experiment indicates that with this restricted material the results were similar to those for the larger number of animals.

\section{Histological, analytical and observational procedures}

The experiment was terminated on day $\mathrm{I} 78$ after starting the pair-feeding. Ethanol was not given during the last 2 days, to preclude immediate after-effects. The animals were killed by decapitation and the blood was collected in heparinized centrifuge tubes. The livers were excised and weighed; specimens for microscopical examination were taken from across the whole left lateral lobe, specimens for electron microscopy from the edge of the same lobe, and the remainder of the liver was further processed for lipid analysis. 
Grading of the liver process and technique of lipid analysis. When the livers were excised, the severity of the liver lesions was rated on the basis of features described by Himsworth (1954), Hoffbauer (1959) and others. A point-scale, I-8, was used for macroscopic grading of the process. Scores were given as follows: I, light colour but smooth surface; 2 , fine granulation of the surface; 3 , very distinct granulation with some nodules on the ventral side; 4 , distinct nodulation on the ventral side, nodulation beginning on the dorsal side; 5 , whole liver nodulated; 6 , heavy nodulation and shrinkage beginning; 7 , shrinkage affecting the whole liver; 8 , extreme shrinkage with nodules appearing as separate rounded bodies. The point values were used for statistical calculations whose validity is examined on p. 652 .

The specimens for microscopic examination were fixed in LAFA, a solution containing $20 \%$ lead acetate, $10 \%$ concentrated formalin, and $70 \%$ of $96 \%$ ethanol (Suomalainen, I954), embedded in paraffin, and stained with haematoxylin-van Gieson. The liver process was rated according to Ahlqvist's ( 1960 ) modification of the method of Hoffbauer (I959) (P1. I). In stage A there is no fibrosis, in stage B fibrosis without so-called nodular regeneration, in stage $C_{1}$ nodular regeneration with no more than five nodules per section across the whole left lateral lobe, and in stage $\mathrm{C}_{2}$ stronger nodular regeneration. The most heavily nodulated livers were regarded as belonging to stage $C_{3}$. Stage $B$ was further divided into two substages, $B_{1}$ and $B_{2}$, by visual estimation of the degree of fibrosis. Numerical scores were given as follows: $A=I$, $\mathrm{B}_{1}=2, \mathrm{~B}_{2}=3, \mathrm{C}_{1}$ and $\mathrm{C}_{2}=4$, and $\mathrm{C}_{3}=5$. The histological examination was carried out without knowledge of the treatment of the animals or of the gross findings at autopsy. The results of the electron microscopy will be reported separately.

The total lipids were determined by the method described by Entenman (1957; procedure 7, p. 307). Samples which could not be processed immediately were stored under nitrogen at $-14^{\circ}$. The fatty-acid composition was determined by gas-liquid partition chromatography, with an apparatus constructed in the laboratory, according to the method of Suomalainen \& Keränen ( $19^{6}{ }_{3}$ ) modified as follows: a Barber-Colemann $\mathrm{Ra}^{226}$ detector was used, and the glass column measured $150 \mathrm{~cm}$ in length and was filled with $35 \%$ Rheoplex-400. In a later series of fatty acid analyses, reported briefly below, chromatography was carried out with a commercial instrument, F and M 870 , provided with a hydrogen flame ionization detector.

Fluid intake. Since water consumption appeared to be high among the rats in group $B$, the fluid consumption of all the animals was measured once daily from day 54 to day 6r. After the administration of ethanol on day $6 \mathrm{r}$ to group $\mathrm{B}$ by gavage, the

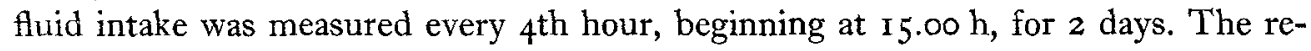
cording of the water consumption was repeated for all the remaining animals in the same manner from day 145 to day 152 , with recordings every 4 th hour for 2 additional days, this time beginning at $\mathrm{I} 1.00 \mathrm{~h}$.

The possible resort to water intake as a measure of hangover was further explored in a later experiment, in which use was made of adult male rats maintained on a standard laboratory diet given ad lib. An intoxicating dose of ethanol $(6 \mathrm{mg} / \mathrm{g}$ by gavage) was administered to one group on alternate days, the controls receiving a corresponding volume of water by gavage. Although the regimen was continued for 
I I o days, the intoxication induced no change in drinking. Thus increased water consumption, reported to follow daily intoxication in chicks (Elhardt, 1930), and dogs and rats (Baisset \& Montastruc, r96r), does not necessarily ensue from less frequently repeated alcoholic intoxication in the rat. The result of this supplementary experiment suggests that additional factors were involved in producing the drinking pattern seen in Fig. 3. Two such factors which might have contributed either separately or in combination are the age of the animals and the composition of the diet.

Total body water. The total body water of all animals was measured on day $7^{2}$. Tritiated water was used as a marker. One $\mathrm{ml}$ of a physiological saline solution, containing $30 \mu \mathrm{c}$, was administered to each animal by intraperitoneal injection with a tuberculin syringe. Blood samples of $20-30 \mu \mathrm{l}$ were taken in duplicate from the tip of the tail, 2 and $4 \mathrm{~h}$ after the injection. The preweighed glass capillaries employed for drawing the samples were placed in tubes for measuring the radioactivity according to the method of Hasan ( 1962 ). After weighing, reagents were added and the tubes sealed. Samples in duplicate for the determination of dry weight were taken into Widmark capillaries $2 \mathrm{~h}$ after the injection, and dried overnight at $50^{\circ}$ followed by $4 \mathrm{~h}$ at $110^{\circ}$. Dilution of the tritiated water was calculated on the basis of determination of radioactivity in the saline solution administered, and by applying the mean value of the radioactivity found in the blood samples. The validity of the method is supported by the results obtained by Foy \& Schnieden (1960) and Kay, Jones \& Smart ( 1966 ), which indicate equilibration of tritiated water within $2-2.5 \mathrm{~h}$ in man, the pig and several species of laboratory animal. This was also checked by preliminary experiments. In one of these a dose of $50 \mu \mathrm{c}$ was given to one animal, followed $4 \mathrm{~h}$ later by a dose of $500 \mu \mathrm{c}$. The radioactivities observed were proportional to the quantities given. In another preliminary trial, $50 \mu \mathrm{c}$ were given to eight animals and samples taken 2,4 and $5.5 \mathrm{~h}$ after injection. The detectable amount of radioactivity was indistinguishable at all time-intervals, suggesting that equilibration was complete after $2 \mathrm{~h}$, and that loss through urine, faeces and evaporation did not affect the results to an extent detectable by the method applied.

Rate of ethanol elimination. The rate of ethanol elimination was determined in ten animals from each group on day $\mathrm{r} 76$. The dose of ethanol was $2 \mathrm{mg} / \mathrm{g}$, given intraperitoneally as a $10 \%(\mathrm{w} / \mathrm{v})$ solution in saline. As several of the animals were in a poor condition, blood samples were taken only twice, 2 and $4 \mathrm{~h}$ after injection. Blood was drawn from the tip of the tail in samples of $0.2 \mathrm{ml}$, which were analysed in duplicate by the alcohol dehydrogenase method, with the test kit of Biochemica Boehringer (Mannheim, W. Germany).

Blood analyses. Samples for haematocrit determination were drawn into capillaries immediately after killing. The cells were sedimented from the bulk of the blood and the plasma was used for determination of the glucose and inorganic ions. The glucose was estimated by means of glucose oxidase, using an enzyme preparation manufactured by Biochemica Boehringer (Mannheim, W. Germany). Calcium, sodium, and potassium were determined by flame photometry using a Beckman B spectrophotometer, and chloride by potentiometric titration.

Ethanol tolerance. The tilting-plane test for alcoholic intoxication described by 
Arvola, Sammalisto \& Wallgren (1958) and Wallgren, Arvola \& Sammalisto (1960) was applied. In testing, the animals are placed head towards the rising slope on a board covered with fine-mesh bronze netting. The board is tilted, and the angle at which the animal slides down is recorded. Six blank tests were made with each animal before the experiment proper, which suffices for establishing a stable level of performance. Performance was measured on two occasions, on days $73-75$ and days $155^{-1} 57$, one-third of the animals in each treatment being tested per day; the order was randomized to avoid systematic errors. The dose of ethanol was $2 \mathrm{mg} / \mathrm{g}$ bodyweight, given intraperitoneally as a $10 \%(\mathrm{w} / \mathrm{v})$ solution in saline. Testing was begun $20 \mathrm{~min}$ after injection and repeated seven times at intervals of $20 \mathrm{~min}$.

Tremor and behaviour in an open field. An attempt was made to detect signs of neurological disturbances indicative of a withdrawal state by measuring the frequency of tremor-like activity. Observations were made on days $162-163$ on two occasions with all the animals. With the animals of group $B$ this was done just before and on the morning after the administration of ethanol. The animals were placed in an aluminium cage weighing $145 \mathrm{~g}$ and resting on rubber tubing. An accelerometer (Type 4332; Brüel and Kjaer, Copenhagen) was connected via an AC-coupled preamplifier (Type i23; Tektronix, Portland, Ore., USA) to an oscilloscope (model 1049, mk IV; Cossor Instruments Ltd, London), and a photographic recording was obtained with a Cossor oscillographic camera (model 1428, mk IIB). Preliminary experiments with rats given tremorine, or kept in the cold, had shown that bursts of tremor-like activity were easily detectable. The animals were observed direct, and recordings were made twice in both sessions at moments when they were quiet. Behaviour was also observed in the Hall open-field test as applied by Broadhurst (1960) and modified by Eriksson \& Wallgren (I966). The test was made on days ${ }_{5} 8$ and 159 of the experiment; each animal was observed once only and the animals in group B were run just before the administration of ethanol.

\section{RESULTS AND DISCUSSION}

\section{Growth rate}

The results of the weekly weighings are shown in Fig. 2. For the interval from I I to 22 weeks after the beginning of pair-feeding, the weights of each animal in the twenty-one surviving pair-fed blocks have been statistically evaluated. The weight records from the last 3 weeks, when only fifteen blocks remained, have been evaluated separately. In the drinking group (A) the growth rate was close to the normal growth in the colony despite the deficient diet. An analysis of variance, of which the results have been summarized in Table 3 , shows that, in comparison with both the controls (group C) and the animals drinking dilute ethanol (group A), repeated intoxication (group B) retarded growth. The difference between the effect of drinking dilute ethanol (A) and receiving an isocaloric amount of oleic acid (C) was also statistically significant.

The effect of giving oleic acid (Fig. 2) showed that some part of the growth retardation attributable to ethanol arose simply from inferior support of growth when part 
Table 3. Results of analysis of variance of the growth results

\begin{tabular}{|c|c|c|c|c|}
\hline \multirow[b]{2}{*}{ Groups } & \multicolumn{2}{|c|}{ Weeks I I -22 } & \multicolumn{2}{|c|}{ Weeks 23-25 } \\
\hline & $\mathrm{F}$ & $P<$ & F & $P<$ \\
\hline $\mathrm{B}<\mathrm{C}$ & $205 \cdot 5$ & 0.001 & 18.5 & 0.001 \\
\hline $\mathrm{B}<\mathrm{A}$ & 485.5 & 0.001 & 23.5 & 0.001 \\
\hline $\mathrm{A}>\mathrm{C}$ & $52 \cdot 5$ & 0.001 & 2.24 & $\mathrm{NS}$ \\
\hline
\end{tabular}

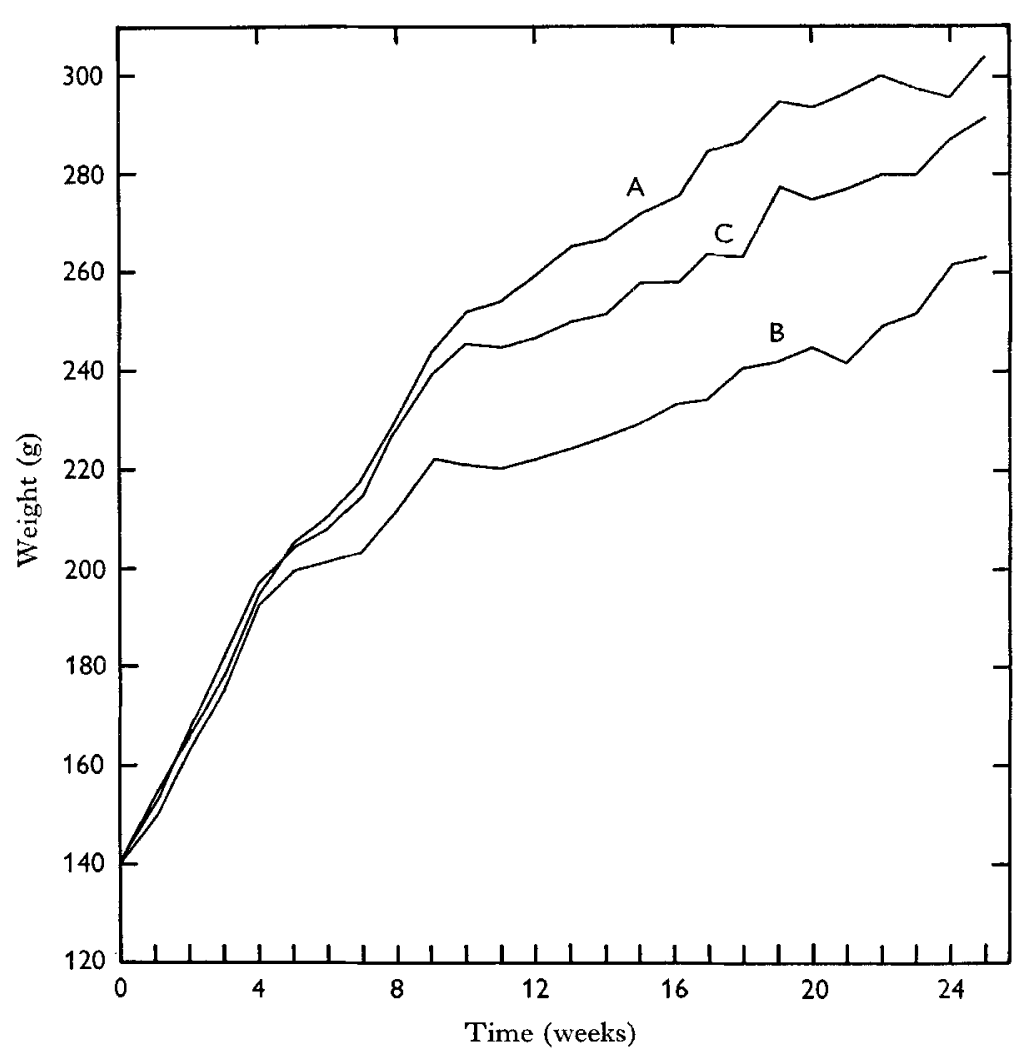

Fig. 2. Growth curves illustrating results of weekly weighings of all rats in the experiment. $\mathrm{A}$, animals drinking dilute ethanol; B, intoxication group; C, controls. Values for twenty-one pair-fed blocks up to the 22nd week, and for fifteen pair-fed blocks during the last 3 weeks.

of the calories are given as repeated shock doses not associated with protective nutrients. The additional effect presumably originated in the stress caused by the pharmacological component of ethanol action. This interpretation is supported by the results for two earlier experimental series comprising forty-four and sixty animals (Suomalainen et al. 1965) in which the depressing effect on growth was markedly intensified when the amount of ethanol given was increased. In the earlier experiments the growth of animals drinking dilute ethanol did not differ from that of animals given water. Findings which point in the same direction have been reported by Mallov (I955), 
although he did not include a control for the altered proportion of total calories to protective nutrients resulting from the incorporation of ethanol in the diet. This was done in the present experiment, but even then growth was retarded. This finding was expected, although the mechanism remains obscure. Determinations of total body water (see p. 655) excluded dehydration as a source of weight differences.

\section{Morphology and lipids of the liver}

The histological picture showed, as expected, fatty infiltration, fibrosis, and nodular regeneration. The ratings of the severity of the liver process are presented in Table 4. Both methods of rating suggest a lower degree of fibrosis after recurrent intoxication than in either the animals drinking dilute ethanol or the controls. In this respect, the last two were very similar. To test the validity of this result, three types of statistical test were applied, of which the results of the analysis of variance are shown in Table 4. The $\chi^{2}$-test was applied to test whether the two-class distribution of the ratings differed. Once again, group B differed significantly from groups A and C. Further, Student's $t$ test was applied with similar findings.

Table 4. Severity of the liver process in fifteen rats of each of groups $A, B$ and $C$ in two ratings made independently

$\begin{array}{lcc}\quad \text { Group } & \begin{array}{c}\text { Macroscopic } \\ \text { rating }\end{array} & \begin{array}{c}\text { Histological } \\ \text { rating }\end{array} \\ \text { A (drinking) } & 5.2 & 3.5 \\ \text { B (intoxication) } & 2.4 & 2.6 \\ \text { C (control) } & 4.2 & 3.3 \\ \text { A > B } & F=8.1 & F=9.4 \\ & P<0.025 & P<0.005 \\ \text { C > B } & F=19.5 & F=7.8 \\ & P<0.005 & P<0.025\end{array}$

Correlation between ratings: $r=+0.85, P<0.001$.

Table 5. Mean values and standard deviations for weights and lipid content of livers of rats ( $n=15)$

\begin{tabular}{|c|c|c|c|}
\hline Group & $\begin{array}{c}\text { Liver } \\
\text { weight } \\
\text { (g) }\end{array}$ & $\begin{array}{c}\text { Liver weight } \\
\text { ( } \% \text { of } \\
\text { body-weight) }\end{array}$ & $\begin{array}{c}\text { Total lipids } \\
\text { in the } \\
\text { liver }(\%)\end{array}$ \\
\hline A (drinking) & $19 \cdot 0 \pm 4.0$ & $6 \cdot 3 \pm 0 \cdot 7$ & $29 \cdot 0 \pm 7 \cdot 2$ \\
\hline $\mathrm{B}$ (intoxication) & $5 \cdot 3 \pm 2 \cdot 6$ & $5.8 \pm 0.6$ & $25 \cdot 5 \pm 5 \cdot 7$ \\
\hline$C$ (control) & $16 \cdot 8 \pm 2 \cdot 5$ & $5.8 \pm 0.6$ & $29 \cdot 0 \pm 5 \cdot 3$ \\
\hline
\end{tabular}

The values for liver weights and total liver fat are summarized in Table 5 ; there were no significant differences between the treatments. Generally, the livers were large and fatty. Suomalainen et al. (1965) had found a larger proportion of stearic acid and a smaller proportion of oleic + linoleic acid in the liver fat of animals undergoing intoxication than in animals drinking dilute ethanol or in control animals drinking water. In the present experiment (Table 6) only the content of stearic acid was slightly greater in the animals undergoing intoxication than in those drinking dilute ethanol. 
The fatty-acid composition of the liver fat and that of the lard used in the diet were similar. Stearic acid seemed to become desaturated, as there was proportionally less of it in the liver, whereas the total quantity of $\mathrm{C}_{18}$ acids was about the same. Arachidonic acid, which is a normal constituent of liver fat, was not found in the lard.

The severity of the liver damage has been graded on the assumption that the condition is progressive while the animal is on a diet. From the experience gained by ourselves and others there is no reason to assume that this is not so. The use, as indices of fibrosis, of the numerical values corresponding to the different stages may be criticized on the ground that, although the stages are supposed to constitute a sequence, they do not represent well-defined, clearly quantitative units. However, the similarity of the results obtained with the two types of rating (correlation coefficient between ratings: $r=+0.85, P<0.001$ ) corroborates the conclusion that the difference in the severity of fibrosis can be regarded as a reliably established finding. For practical reasons, the macroscopic rating could not be made by a double-blind procedure. However, the histological grading was performed in this manner, and strengthens the conclusion that the findings are reliable.

Table 6. Fatty-acid composition (molar percentage) of liver lipids of rats subjected to different treatments, compared with that of a sample of the purified lard used in the diet

\begin{tabular}{|c|c|c|c|c|c|c|c|c|c|}
\hline & $\mathrm{C}_{14}$ & $\mathrm{C}_{16}$ & $C_{16: 1}$ & $\mathrm{C}_{1 \mathrm{~B}}$ & $\mathrm{C}_{18: I}$ & $\mathrm{C}_{18: 2}$ & $\mathrm{C}_{18: 3}$ & $\mathrm{C}_{20}$ & $\mathrm{C}_{20: 4}$ \\
\hline Group & 0.78 & $28 \cdot 58$ & $2 \cdot 48$ & 6.04 & 50.06 & 7.98 & 0.45 & I. 34 & $x \cdot 66$ \\
\hline Group B & 0.79 & 29.0 & $2 \cdot 04$ & $7 \cdot 49$ & $48 \cdot 53$ & $8 \cdot 16$ & 0.56 & $\mathrm{I} .53$ & $2 \cdot 02$ \\
\hline Group C & 0.64 & $29 \cdot 19$ & I.73 & 7.04 & $49 \cdot 42$ & $8 \cdot 20$ & 0.53 & $I \cdot 36$ & $1 \cdot 86$ \\
\hline Lard & 1.42 & $28 \cdot 77$ & $2 \cdot 00$ & 17.95 & $42 \cdot 74$ & $5 \cdot 55$ & 0.57 & 1.00 & \\
\hline
\end{tabular}

Summary of statistical evaluation of the differences in stearic acid content

$\begin{array}{lcccc} & \text { F } & P< & t & P< \\ \mathrm{B}>\text { A } & 9.47 & 0.0 \text { I } & 2.49 & 0.025 \\ \mathrm{~B}>\text { C } & \mathrm{I} .39 & - & \mathrm{I} \cdot 15 & - \\ \mathrm{A}<\mathrm{C} & 4.30 & - & 3.84 & 0.005\end{array}$

As has been pointed out by Hoffbauer (1959), there is no ideal system of grading fibrosis of the liver. The method applied in the present experiment seems suitable for grading specimens of fatty fibrosis of the liver in rats, and our opinion is that it is as reliable as any single observation-for example, the relative volume of the trabeculae in the liver used by Ahlqvist (1960).

The finding that the severity of the liver process was less pronounced in the series of animals receiving intoxicating doses of ethanol admits of no simple explanation; relevant factors include nutritional balance, growth rate, and ethanol toxicity.

The contribution of ethanol to the total number of calories supplied by the diet was small. The control group showed that the regimen as such induced fibrosis even without ethanol. In a preliminary experiment, a diet of a composition similar to that used in the present experiment, except that it contained 10\% protein, induced fatty liver only, whereas fibrosis ensued in all animals receiving that diet and $10 \%(\mathrm{w} / \mathrm{v})$ ethanol as sole fluid. The ethanol contributed $20 \%$ of the total calories, and so shifted the nutritional balance to cause fibrosis. Hence, the present findings agree with 
the commonly accepted finding (Klatskin, I96r ; Lieber, 1965 ; Hartroft \& Porta, I966) that ethanol contributes to the development of fibrosis largely by reason of its impact on nutrition. This notion is in accordance with opinions on human cirrhosis (Himsworth, 1954).

Another question is whether the fatty infiltration of acute alcoholic intoxication contributes to the development of liver damage. The present findings do not exhibit such a relationship, which is perhaps unexpected. Release of free fatty acids from adipose tissue and their incorporation in triglycerides of the liver has been demonstrated in a large number of experiments involving acute administration of ethanol. The release of free fatty acids can be reproduced also in chronic alcoholics (Schapiro, Scheig, Drummey, Mendelson \& Isselbacher, 1965). It is not known whether the process, if repeated, aggravates the fatty infiltration of the liver attributable to nutritional imbalance. Some previous evidence indicates that in prolonged experiments intoxication-induced deposition of triglycerides may be compensated. Thompson, Takimura \& Sher (1963), using guinea-pigs, and Dajani, Ghandur-Mnaymneh, Harrison \& Nassar (1965), using rats, gave moderately intoxicating doses of ethanol daily while maintaining the animals on adequate diets. They found a temporary increase in liver lipids, followed later by a return to the normal level despite continued administration of ethanol. The nature of the compensatory reaction is not known, but the observation serves to underscore the fact that, in this field, the results of shortterm experiments cannot be applied direct to those from long-term studies.

As regards the problem of whether a direct toxic effect of ethanol is a factor contributing to this liver damage, the results obtained were again negative, and in agreement with those cited above. Combined electron microscopical and biochemical study suggests that there is some disturbance of ultrastructure and lipid metabolism in liver cells in acute intoxication (Ashworth, Wrightsman, Cooper \& Di Luzio, I965; Stein \& Stein, 1965), but there is no clue as to their possible significance for the development of pathological alterations in long-term use of alcohol. The findings in the present study suggest that repeated elevation of the concentration of ethanol in the organism does not accelerate the development of liver lesions. Theories suggesting a direct toxic action of ethanol are thus not supported. Nevertheless, it is possible that, had intoxicating doses of ethanol been given daily, they might have produced carryover effects not observed in this experiment.

The slower growth rate of the animals in group B may have made the liver lesions less severe. It is known that the development of experimental nutritional fibrosis is accelerated by an increased rate of growth (cf. Hartroft, 1961). Porta \& GomezDumm (I966) have reported a similar relationship between the development of liver lesions and growth rate with rats receiving ethanol. Schmähl, Thomas, Sattler \& Scheld ( $\left(9^{6} 65\right)$ found that when extremely large quantities of a commercial brandy containing $38 \%$ ethanol were administered to rats, growth was strongly depressed, but neither fibrosis nor other lesions of the liver were observed.

The effect of ethanol on the fatty-acid composition of liver fat was slight, appearing to be masked in the control group by the oleic acid. In view of the previous finding of Suomalainen et al. (1965) with fewer animals, a further experiment was made to check 
whether repeated intoxication alters the fatty-acid composition of liver lipids. Rats were maintained on standard laboratory diet given ad lib., one group drinking dilute ethanol and the other receiving the same quantity of ethanol by gavage every other day. The fatty-acid composition of the liver lipids and interscapular and intestinal depot fat were analysed after 3 months, but no effect of the different treatments was discernible.

\section{Water balance}

Fluid intake. The results are summarized in Table 7 and Fig. 3. The values in the table show a general diminution in fluid consumption during the later period of observation. However, the strikingly high water consumption of the animals given the intoxicating doses of ethanol is more conspicuous. The difference, as compared with both the other series of animals, is significant at the $0.1 \%$ level (Student's $t$ test). A further noteworthy feature is the peak of water consumption during the night, which was much greater in group B (Fig. 3). Statistical evaluation, with values derived from

Table 7. Mean values and standard deviations for fluid consumption (ml/1oo g body-weight per day) of the rats subjected to three different regimens

$\begin{array}{lcc}\text { Group } & \begin{array}{c}\text { Days } 54-63 \text { of } \\ \text { the experiment } \\ (n=24)\end{array} & \begin{array}{c}\text { Days } 145-154 \text { of } \\ \text { the experiment } \\ (n=21)\end{array} \\ \text { A (drinking) } & 6 \cdot 02 \pm \mathrm{I} \cdot 07 & 4 \cdot 37 \pm \mathrm{I} \cdot 30 \\ \text { B (intoxication) } & 12 \cdot 32 \pm 5 \cdot 97 & 8 \cdot 9 \mathrm{I} \pm 3 \cdot 93 \\ \text { C (control) } & 6 \cdot 05 \pm 0.8 \mathrm{I} & 4 \cdot 67 \pm \mathrm{I} \cdot 30\end{array}$

the four complete 2 -day cycles in each observational period, showed that in group B consumption during the Ist night following intoxication differed significantly from that during the 2 nd night ( $\mathrm{F}$ for the first period $=\mathrm{I}_{3} \cdot \mathrm{I} 5$, df $\mathrm{I} / \mathrm{I} 90, P<0.00 \mathrm{I} ; \mathrm{F}$ for the second period $=7.85$, df $1 / 166, P<0.01$ ). When the average fluid intake of group $B$ during the 2 nd day was compared with the average daily consumption of fluid by both the other groups, it still proved to be significantly greater $(P<0.001)$. The results presented in Table 7 further suggest large individual differences in group B. There was some overlap between group B and groups A and C, but most of the rats in group $B$ drank much more. The correlation between the average consumption of the animals in group B during the first and the second periods of observation was calculated. The rank-order correlation factor $r$ was $+0.53(P<0.01)$. In view of the time-lapse of 3 months between the two measuring periods, this suggests that individual differences exist in the sensitivity of the regulation of the water balance to the intoxicating doses of ethanol.

The high and variable water consumption of the rats in the intoxication group was first regarded as a potential measure of the after-effects of ethanol. If a direct relationship exists between the after-effect and the excessive water consumption, a peak in the drinking should come at a definite time-interval after the administration of ethanol. Nevertheless, the main part of the water consumption fell within the same hours in both series of measurements although the time of administration differ 
Total body water. In the animals subjected to repeated intoxication (group B), body water amounted to $54.4 \pm 3.1 \%( \pm \mathrm{SD})$, as compared with $50.9 \pm 3.5 \%$ in group $A$ and $48 \cdot I \pm 3.3 \%$ in group C. Evaluation by Student's $t$ test showed that the difference was significant (B $>\mathrm{A}, P<0.0 \mathrm{I} ; \mathrm{B}>\mathrm{C}, P<0.00 \mathrm{r})$. The low values in all groups were probably due to obesity.

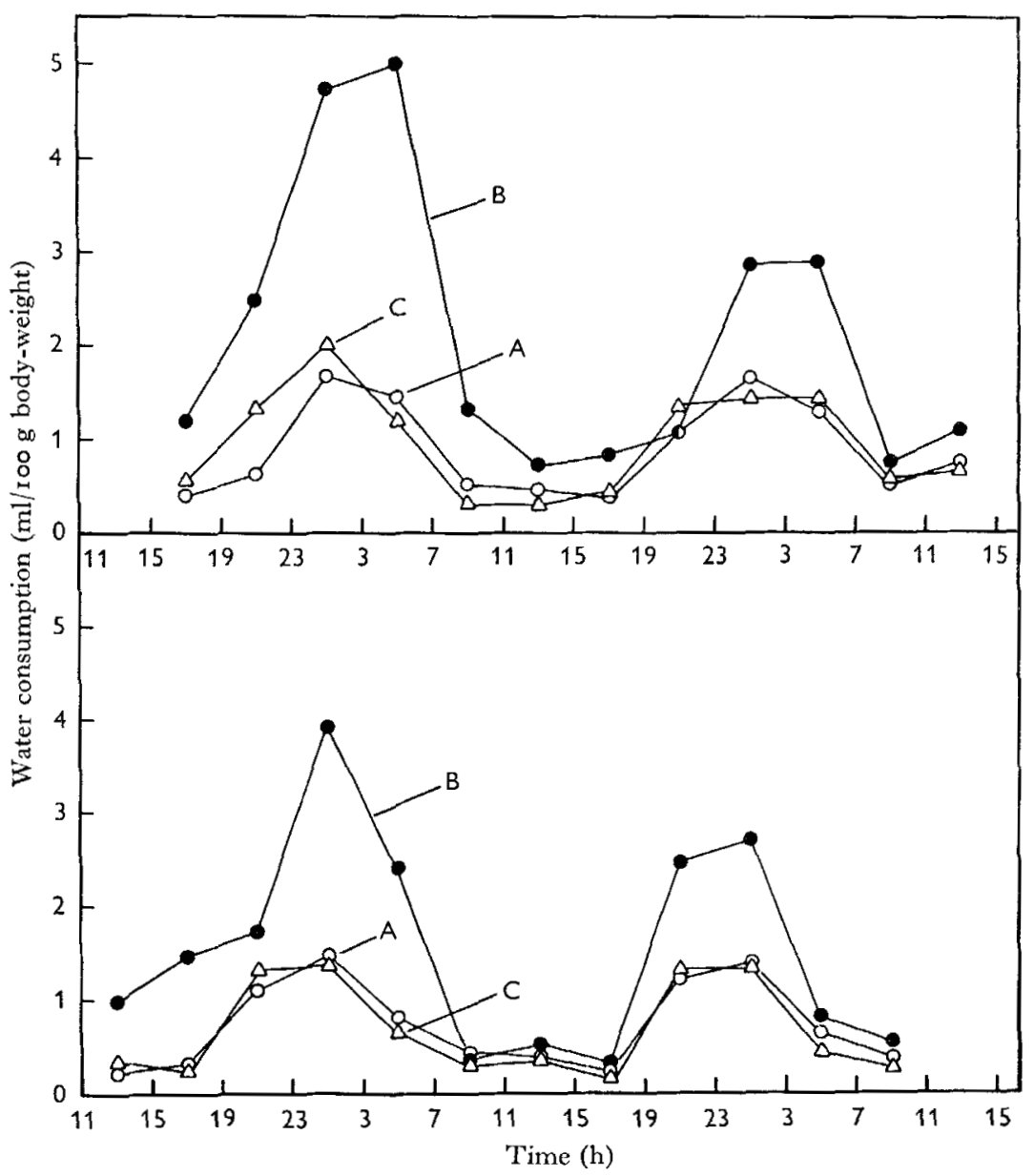

Fig. 3. Fluid consumption measured at $4 \mathrm{~h}$ intervals over $48 \mathrm{~h}$, after administration of an intoxicating dose of ethanol to the animals in group $B(\mathcal{O})$ and oleic acid by gavage to the animals in group $C(\triangle)$. $O$, animals drinking dilute ethanol (group $A$ ). Ethanol was given to group $B$ immediately before start of observation at $15.00 \mathrm{~h}$ in the first measuring period (days $61-63$, upper graph), and at $11.00 \mathrm{~h}$ in the second period (days $15^{2-154}$, lower graph).

\section{Rate of ethanol elimination}

The results are presented in Table 8 . Widmark's factor $r$ is an estimate of the space in the body where ethanol would be present if it were evenly distributed in the same concentration as in the blood. One step in obtaining values of $r$ is to determine the slope of the blood ethanol curve in the elimination phase and extrapolate it to the ordinate. As blood samples were drawn at two times only, the estimates of the factor $r$ 
for individual rats, and consequently for individual rates of elimination, are not exact. However, the analysis of variance clearly demonstrates lower and more rapidly falling concentrations of blood ethanol in the animals subjected to repeated intoxication.

The effect of prolonged ethanol administration on the rate of elimination of ethanol is controversial (for review, see Elbel \& Schleyer, 1956); some authors report increased rates of elimination in rats (Hawkins, Kalant $\&$ Khanna, I 966) and others have found no change (Greenberger, Cohen \& Isselbacher, 1965). The present result (Table 8) apparently supports the finding by Hawkins et al. (1966). The validity of the conclusion is weakened by the lesser degree of cirrhosis in the rats undergoing intoxication, since dietary fibrosis depresses the rate of oxidation of ethanol in rats (Mikata, Dimakulangan \& Hartroft, 1963).

Table 8. Rate of fall of blood ethanol levels on day ${ }^{7} 76$ of pair-feeding in ten rats from each treatment which were given $2 \mathrm{mg}$ ethanollg body-weight by intraperitoneal injection

(The mean rates of ethanol elimination in the last column were estimated on the basis of Widmark's factor $r$. The blood ethanol concentrations are expressed in $\mathrm{mg} / \mathrm{ro0} \mathrm{ml} \mathrm{blood}$, and given with standard deviations. $\beta_{60}$ shows the rate of decrease of the blood ethanol concentration in $\mathrm{mg} / 100 \mathrm{ml}$ per $\mathrm{h}$ )

\begin{tabular}{|c|c|c|c|c|}
\hline \multirow[b]{3}{*}{ Group } & \multicolumn{2}{|c|}{ Blood ethanol (mg/roo ml) } & \multirow{2}{*}{\multicolumn{2}{|c|}{ Elimination rate }} \\
\hline & & & & \\
\hline & injection & injection & $\beta_{60}$ & $(\mathrm{mg} / \mathrm{kg} \mathrm{h})$ \\
\hline A (drinking) & $212 \pm 24$ & $217 \pm 24$ & 47 & 245 \\
\hline $\mathrm{B}$ (intoxication) & $169 \pm 22$ & $48 \pm 19$ & 60 & 330 \\
\hline $\mathrm{C}$ (control) & $201 \pm 31$ & $108 \pm 35$ & 46 & 238 \\
\hline 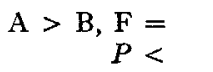 & $\begin{array}{l}\text { I } 7 \cdot 5 \\
0.005\end{array}$ & $\begin{array}{l}5 r \cdot 3 \\
0 \cdot 001\end{array}$ & & \\
\hline 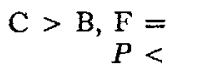 & $\begin{array}{l}6.9 \\
0.025\end{array}$ & $\begin{array}{l}23 \cdot 2 \\
0.001\end{array}$ & & \\
\hline
\end{tabular}

\section{Changes in the blood}

The mean of the haematocrit readings was 30.2 after treatment $A$ (drinking dilute ethanol), $32 \cdot 9$ after treatment $B$ (repeated intoxication), and $32 \cdot 3$ in the controls. The values are sufficiently low to show anaemia. A significant negative correlation was found between the haematocrit values and the estimated severity of the liver lesions in the macroscopic rating $(r=-0.78, P<0.001)$.

The blood sugar values (Table 9) appeared to be normal (Spector, I956). The lower values after repeated intoxication were not statistically significant. The values for plasma electrolytes are presented in Table $\mathbf{~} 0$. In only one instance was the $5 \%$ level of significance reached; plasma potassium of the group B rats exceeded that of the controls at this level. Plasma calcium fell with increase in the severity of the liver process, as is indicated by a significant negative correlation with the numerical values for the macroscopic rating $(r=-0.59, P<0.001)$.

Anaemia is a common finding in human alcoholic cirrhosis (Herbert, Zalusky \& Davidson, 1963). The negative correlation between haematocrit values and the degree of fibrosis in the present results indicates a similarity in the pathology of rats and man. Moreover, the finding that plasma levels of calcium tended to diminish 
Table 9. Mean values with standard deviations and ranges for blood sugar values of the rats subjected to different treatments (fifteen animals in each treatment)

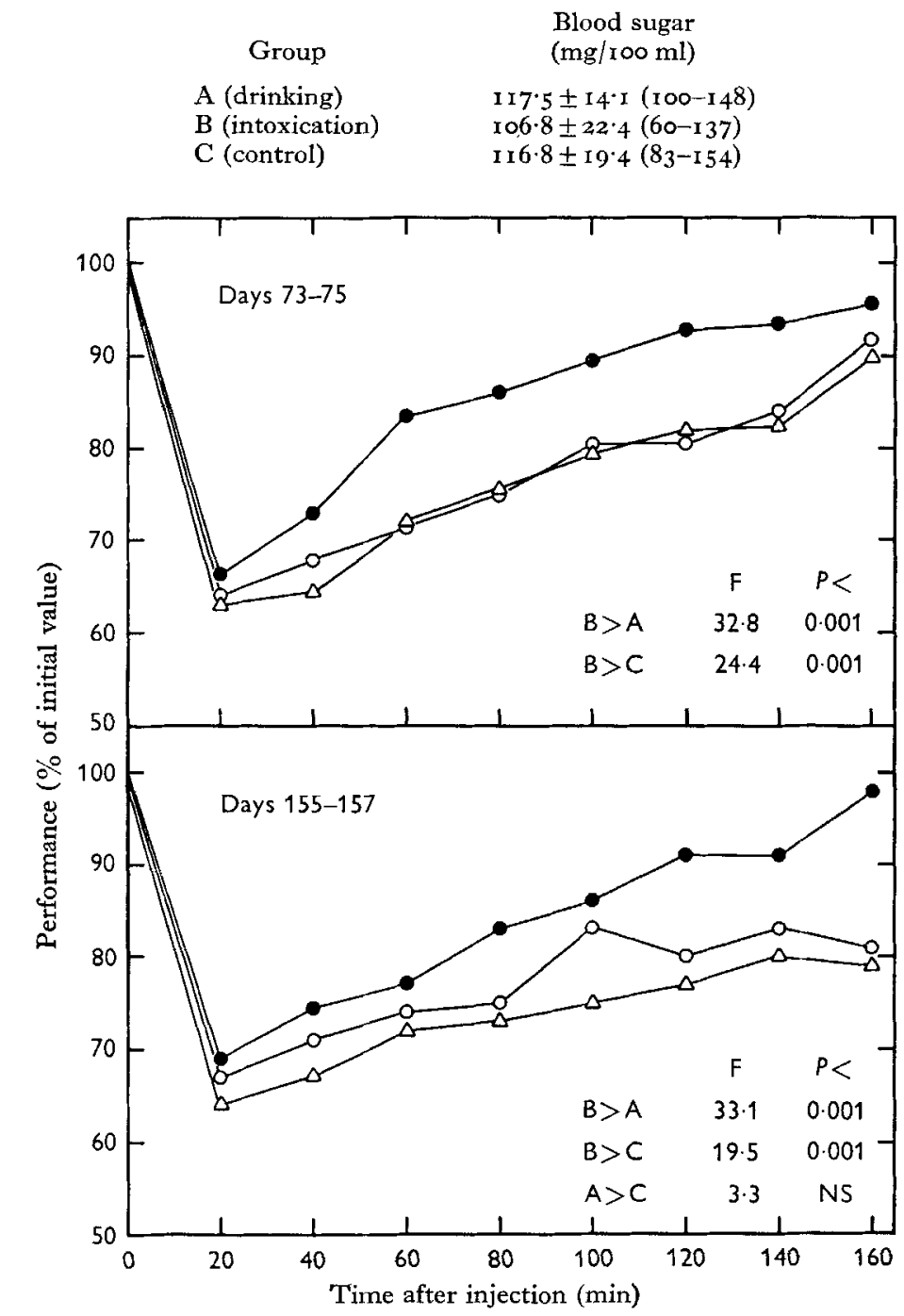

Fig. 4. Performance of rats in the tilted-plane test (see p. 649). $O$, drinking (A); 0 , intoxication (B); $\triangle$, control (C). The number of pair-feeding blocks was twenty-four on days $73-75$, and twenty-one on days 155-157. Evaluation of differences between the levels was made by analysis of variance, of which the result is indicated in the graphs.

with increasing severity of fibrosis has also been observed in man (Bland, I963). 'The electrolytes were not affected.

The variation in blood glucose seems to be larger in group $\mathrm{C}$ than in group $\mathrm{A}$, but the distribution is symmetrical around a mean value similar to that found in group $A$. The lower mean in group B is attributable to some aberrantly low values. This accordingly suggests a possibility of individual hypoglycaemia in rats undergoing 
repeated intoxication, but the experiment was too small to permit of firm conclusions. As hypoglycaemia is characteristic of the hangover phase (Vartia, Forsander \& Krusius, I960), it is not entirely out of the question that the low values found in the intoxication may reflect immediate after-effects of alcoholic intoxication rather than a more permanent disturbance of the carbohydrate metabolism.

Table Io. Mean values (mM) and standard deviations for plasma electrolytes in rats subjected to different treatments at termination of the experiment ( $A$ and $B, n=14 ; C$, $n=15$ )

\begin{tabular}{|c|c|c|c|c|}
\hline Group & $\mathrm{Ca}$ & $\mathrm{K}$ & $\mathrm{Na}$ & $\mathrm{Cl}$ \\
\hline $\begin{array}{l}\text { A (drinking) } \\
\text { B (intoxication) } \\
\text { C (control) }\end{array}$ & $\begin{array}{l}2.47 \pm 0.17 \\
2.57 \pm 0.09 \\
2.58 \pm 0.16\end{array}$ & $\begin{array}{l}5.76 \pm 0.43 \\
5.95 * \pm 0.28 \\
5.68 * \pm 0.37\end{array}$ & $\begin{array}{l}I 42^{\prime} \mathrm{I} \pm \mathrm{I} \cdot 47 \\
\mathrm{I} 42^{\prime} \cdot 9 \pm \mathrm{I} \cdot 28 \\
\mathrm{I} 42 \cdot 7 \pm \mathrm{I} \cdot 64\end{array}$ & $\begin{array}{l}108.0 \pm 2.30 \\
\text { 108.7 } 2.94 \\
\text { 108.8 } 2.86\end{array}$ \\
\hline
\end{tabular}

\section{Behavioural measures}

Ethanol tolerance. The performance of the animals in the tilted-plane test is presented in Fig. 4. The difference between the levels of performance was evaluated by analysis of variance. In both tests, the animals subjected to intoxication (group B) were significantly less affected than the animals in groups $\mathrm{A}$ and $\mathrm{C}$.

The results on the two different test occasions were very similar. On the later one, the more rapid elimination of ethanol in group B seemed to affect the results, but since the level of performance was higher in this group after all intervals, true tolerance at the tissue level seemed to be involved. It is also evident that tolerance was not further increased from days $73^{-} 75^{\text {to days }} 155^{-1} 57$.

Tremor and behaviour in an open field. Neither tremor nor behaviour in the openfield test was found to differ significantly after the various treatments.

The performance in the open field was very similar to that found in normal rats from the laboratory colony (Eriksson \& Wallgren, unpublished findings), which indicates that this type of behaviour in the conditions of measurement is resistant to an adverse dietary regimen and changes in the general physical state of the animals.

\section{General comment}

The basic procedure employed in this experiment, involving different temporal distribution of ethanol administration under conditions of controlled dietary intake, is laborious, but seems well suited to the evaluation of the respective contributions made by pharmacological and nutritional factors to the overall effects of prolonged use of alcohol. A pair-feeding technique was used, as it is a common experience in experiments on nutrition that complications arise from individual differences in requirements if unmatched animals are maintained for prolonged periods on isocaloric rations. The very small variation in calorie intake resulted in part from the initial screening of the rats. Presumably, the variation was also diminished by the procedure of giving food in amounts proportional to the body-weight. The slower rate of growth in rats undergoing intoxication contributed to the slightly higher mean calorie intake in that group. 
One of the problems involved in undertaking this type of experiment is the size of the ethanol dose. If the doses used are too large, a serious loss of animals may result. In the present study, gradual intensification of the conditions was used successfully.

The criteria chosen showed an effect of the intoxication on some of the factors studied. The reduction in growth rate was mainly caused by a pharmacological effect of ethanol, but the exact mechanism remains obscure. The increased consumption of water is presumably attributable to intoxication-induced disturbance of the posthypophyseal function. The moderation of liver damage was unexpected, and invites further study. With respect to the aetiology of liver damage in the chronic use of alcohol, an important conclusion is that our findings do not support the role of a direct hepatotoxic effect exercised by ethanol. In one of the preliminary experiments the adrenal glands were examined but did not reveal differential effects of treatment.

Except as regards the increase in nervous tolerance, found to be unaltered over a relatively long period, the behavioural measures gave negative results. Either the tests used were not suitable or the pharmacological effect of intoxication was insufficiently strong to induce marked changes.

Our thanks are due to the students who assisted in the routine work, to Mrs Helkky Heinilä for her able technical assistance at various stages of the testing, to $\mathrm{Mr} \mathrm{A}$. J. A. Keränen and Dr Elke Parkkinen for determining the fatty-acid composition of the liver lipids, and to Dr J. Hasan of the Institute of Occupational Health for his help in the body-water determinations. The work was supported in part by a grant from the Signe and Ane Gyllenberg Foundation.

\section{REFEREN CES}

Ahlqvist, J. (1960). Acta path. microbiol. scand. 50, Suppl. 142.

Arvola, A., Sammalisto, L. \& Wallgren, H. (1958). Q. भl Stud. Alcohol 19, 563.

Ashworth, C. T., Wrightsman, F., Cooper, B. \& Di Luzio, N. R. (1 965). F. Lipid Res. 6, 258.

Baïsset, A. \& Montastruc, P. (196r). C. r. Séanc. Soc. Biol. 155, i 128.

Bland, J. H. (1963). Clinical Metabolism of Body Water and Electrolytes. Philadelphia and London: Saunders.

Broadhurst, P. L. (I960). In Experiments in Personality. Vol. I. Psychogenetics and Psychopharmacology, p. I. [H. J. Eysenck, editor.] London: Routledge and Kegan Paul.

Dajani, R. M., Ghandur-Mnaymneh, L., Harrison, M. \& Nassar, T. (1965). F. Nutr. 86, 29.

Elbel, H. \& Schleyer, F. (1956). Blutalkohol. Die wissenschaftlichen Grundlagen der Beurteilung von Blutalkoholbefunden bei Strassenverkehrsdelikten. 2. Aufl. Stuttgart: Georg Thieme.

Elhardt, W. E. (1930). Am. F. Physiol. 92, 450.

Entenman, C. (1957). In Methods in Enzymology. Vol. 3, p. 299. [S. P. Colowick and N. O. Kaplan, editors.] New York: Academic Press Inc.

Eriksson, K. \& Wallgren, H. (1966). Acta physiol. scand. 68, Suppl. 277, p. 46.

Foy, J. M. \& Schnieden, H. (1960). F. Physiol., Lond. 154, I69.

Greenberger, N. J., Cohen, R. B. \& Isselbacher, K. J. (1965). Lab. Invest. 14, 264.

György, P. \& Goldblatt, H. (I949). F. exp. Med. 89, 245.

Hartroft, W. S. (1961). In Progress in Liver Diseases. Vol. I, p. 68. [H. Popper and F. Schaffner, editors.] New York and London: Grune and Stratton.

Hartroft, W. S. \& Porta, E. A. (1966). Nutr. Rev. 24, 97.

Hasan, J. (1962). In Tritium in the Physical and Biological Sciences. Vol. I, p. 36 I. Vienna: International Atomic Energy Agency.

Hawk, P. B., Oser, B. L. \& Summerson, W. H. (1954). Practical Physiological Chemistry, I3th ed. London: J. \& A. Churchill.

Hawkins, R. D., Kalant, IH. \& Khanna, J. M. (1966). Can. F. Physiol. Pharmacol. 44, 24 I. 
Herbert, V., Zalusky, R. \& Davidson, C. S. (1963). Ann. intern. Med. 58, 977.

Himsworth, H. P. (1954). Lectures on the Liver and its Diseases. Oxford: Blackwell.

Hoffbauer, F. W. (1959), Archs. Path. 68, 160.

Kay, M., Jones, A. S. \& Smart, R. (1966). Br. F. Nutr. 20, 439.

Klatskin, G. (I96I). Gastroenterology, 4I, 443.

Lieber, C. S. (1965). In Progress in Liver Diseases. Vol. 2, p. 134. [H. Popper and F. Schaffner, editors.] New York and London: Grune and Stratton.

Mallov, S. (1955). Proc. Soc. exp. Biol. Med. 88, 246.

Mikata, A., Dimakulangan, A. A. \& Hartroft, W. S. (I963). Gastroenterology 44, 159.

Porta, E. A. \& Gomez-Dumm, C. L. A. (1966). Fedn Proc. Fedn Am. Socs exp. Biol. $25,304$.

Schapiro, R. H., Scheig, R. L., Drummey, G. D., Mendelson, J. H. \& Isselbacher, K. J. (1965). New Engl. F. Med. 272, 610 .

Schmähl, D., Thomas, C., Sattler, W. \& Scheld, G. F. (1965). Z. Krebsforsch. 66, 526.

Spector, W. S. (editor) (I 956). Handbook of Biological Data. Philadelphia and London: Saunders.

Stein, O. \& Stein, Y. (1965). Israel F. med. Sci. I, 378.

Suomalainen, H. \& Keränen, A. J. A. (I963). Biochim. biophys. Acta 70, 493.

Suomalainen, H., Wallgren, H. \& Åhman, K. (1965). Alkoholikysymys 33, I 8 .

Suomalainen, H. O. T. (1954). Suomal. eläin- ja kasvit. Seur. Van. Fulk. r6, no. 7.

Thompson, J. R., 'Takimura, Y. \& Sher, B. C. (1963). Am. Rev. resp. Dis. 88, 89 (Abstr. Q. $\mathscr{f l}$ Stud. Alcohol $\mathrm{r} 965,26,33 \mathrm{I}$ ).

Vartia, K. O., Forsander, O. A. \& Krusius, F.-E. (1 960). Q. $7 l$ Stud. Alcohol 21, 597.

Wallgren, H., Arvola, A. \& Sammalisto, L. (1960). Q. Il Stud. Alcohol 2r, 698.

Wallgren, H. \& Suomalainen, H. (1 966). Acta physiol. scand. 68, Suppl. 277, p. 2 I 8.

\section{EXPLANATION OF PLATE}

Low-power magnification of the histological picture of livers of rats classified as belonging to the stages $\mathrm{B}_{1}, \mathrm{~B}_{2}, \mathrm{C}_{1}, \mathrm{C}_{2}$ and $\mathrm{C}_{3}$ described on $\mathrm{p}$. 647 . Increasing fibrosis with successive accentuation of nodular regeneration is seen. The picture also should give an impression about the alterations in size of the liver during the development of fibrosis. Magnitude approximately $\times$ Io. 
British Gournal of Nutrition, Vol. 21, No. 3

Plate I

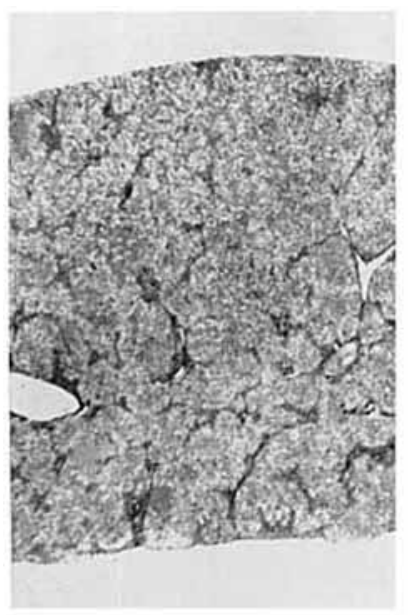

$\mathrm{B}_{1}$

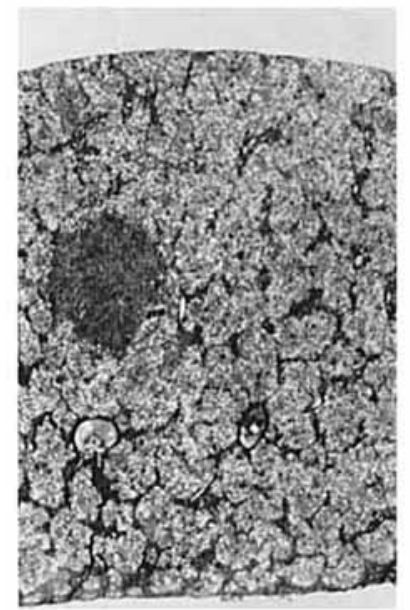

$\mathrm{C}_{1}$

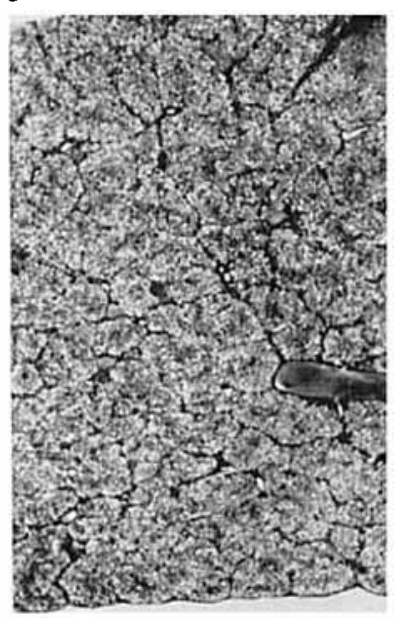

$\mathrm{B}_{2}$

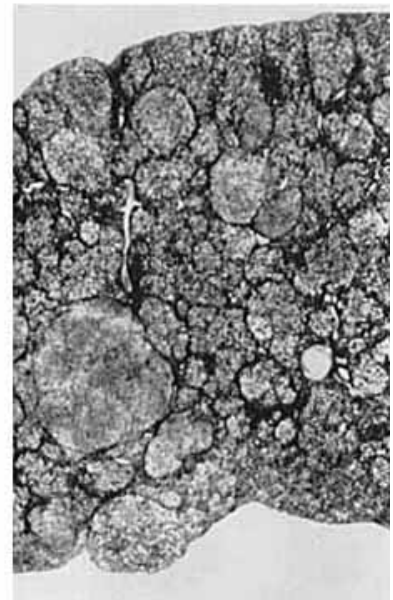

$\mathrm{C}_{2}$

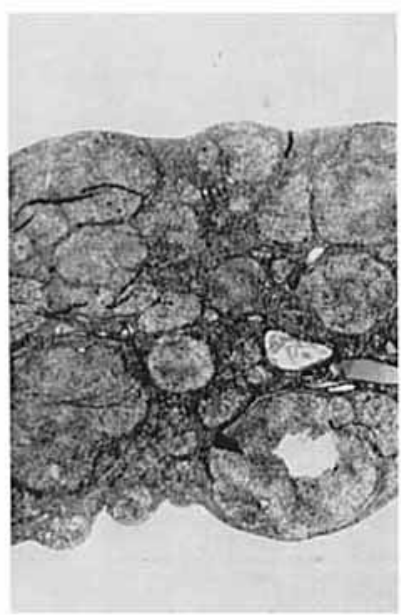

$\mathrm{C}_{3}$ 